DOI: $10.17805 /$ trudy.2017.3.5

\title{
ВЗАИМОСВЯЗЬ ПОКАЗАТЕЛЯ «СООТВЕТСТВИЕ ГЕНДЕРНОМУ СТЕРЕОТИПУ» С ЛИЧНОСТНОЙ ТРЕВОЖНОСТЬЮ И САМООЦЕНКОЙ
}

\author{
А. И. Полянский, Е. А. Сухарева \\ Московский гуманитарный университет
}

\begin{abstract}
Аннотация: Анализируется вопрос о взаимосвязи самооценки и тревожности личности с показателем соответствия гендерному стереотипу. При изучении гендерных стереотипов был сделан вывод о том, что они, по сути, есть порождающиеся обществом обобщённые и устойчивые представления о мужчинах и женщинах.
\end{abstract}

Ключевые слова: гендерный стереотип; личностная тревонность; самооценка; маскулинность; фемининность; андрогиния; самооценка личности

\section{RELATIONSHIP OF THE INDICATOR “ACCORDANCE WITH THE GENDER STEREOTYPE” TO PERSONAL ANXIETY AND SELF-ESTEEM}

\author{
A. I. Polyansky, E. A. Sukhareva \\ Moscow University for the Humanities
}

Abstract: The paper analyses the issue of the relationship of self-esteem and personal anxiety to the "accordance with the gender stereotype" indicator. Studying gender stereotypes the authors drew the conclusion that those are per se society-generated, generalized and persistent concepts of men and women.

Keywords: gender stereotype; personal anxiety; self-esteem; masculinity; femininity; androgynism; personal self-esteem

Теоретико-методологической основой исследования является гендерный подход в психологии (Бендас, 2009; Берн, 2008; Клёцина, 2004; Ожигова, 2006).

В последнее время слово «стереотип» воспринимается и трактуется как некое орудие для борьбы с индивидуальностью. Разумеется, стереотипы не всегда выражают свой положительный эффект, и, тем не менее, именно они дают нам некие предположения о том, как поступать в той или иной ситуации, какую выбрать манеру поведения, какая роль подходит именно нам. Особо резкой критике подвергаются гендерные стереотипы: женщины всё чаще посвящают свою жизнь работе, старясь доказывать тем самым, что стереотип о женщине-матери в наше время уже не актуален. Многие мужчины соглашаются на роль «домохозяина». 
Также на современном этапе развития российского общества многие учёные отмечают феномен феминизации (Э. А. Понуждаев, А. А. Лобова, Л. Г. Бригаднова, Г. И. Пещеров, Е. А. Валькова и др.), который подвергает изменению бытующие гендерные стереотипы.

Особенно острым в свете данных изменений представляется вопрос о соответствии гендерному стереотипу. Данная проблема необычайно интересна и базисна по своей сути, поскольку включена в поле вопросов о самопознании, самоидентификации личности (Козлов, Шухова,2010).

В первую очередь, интересен вопрос о взаимосвязи самооценки и тревожности личности с показателем соответствия гендерному стереотипу: высокая тревожность - одно из немногих личностных свойств, которое на протяжении веков приписывают исключительно женщинам. В свете кризисной ситуации в нашем обществе нам было интересно узнать, сохраняет ли силу подобный стереотип. Изучение же взаимосвязи самооценки и соответствия гендерному стереотипу рассматривалось в свете большего раскрытия феномена личности как такового: насколько соответствие гендерному стереотипу связано с оценкой личностью самой себя?

Для изучения взаимосвязи приверженности и соответствия гендерному стереотипу с уровнем тревожности и самооценкой личности были отобраны следующие методики: методика «Я мужчина/Я женщина» Л. Н. Ожиговой, методика измерения уровня тревожности Тейлора (в адаптации Норакидзе), методика изучения интегральной самооценки личности «Кто я есть в этом мире» Ю. М. Забродина, В. В. Новикова. В качестве метода, выбранного для математической обработки данных в целях выявления взаимосвязи между показателями, выступал коэффициент ранговой корреляции Спирмена (rs). Для выявления различий в исследуемых признаках между группами мужчин и женщин был выбран $\mathrm{U}$-критерий Манна-Уитни (Сидоренко, 2003). Выборка составила 60 человек (30 мужчин и 30 женщин соответственно): жители города Москва, с разным уровнем образования и семейным положением. Исследование проводилось в январе-марте 2015 г.

Прежде чем перейти к результатам, необходимо пояснить формулировку первого изучаемого признака - «соответствие гендерному стереотипу».

Что касается результатов исследования - сразу же необходимо отметить, что интерпретация полученных данных не носит догматический характер, а являет собой только лишь наши предположения касательно результатов исследования.

В ходе исследования была выявлена обратная слабая корреляционная связь между показателем соответствия гендерному стереотипу и тревожностью личности. В объяснении мы исходим из того понимания, что 
соответствие/несоответствие гендерному стереотипу является одним из аспектов, способных вызывать тревожность, как чувство беспредметного беспокойства и переживания.

Делая основной упор на социум, мы видим следующую картину: женщина, осознавшая себя как представительницу феминности, избирает и соответствующую ей модель поведения. Общество, встречая такое соответствие гендерным стереотипам, не высказывает недовольства, напротив, оценивает адекватно, не продуцируя факторы, способные вызвать тревожность, будь то непринятие, критика, избегание и т. д., следовательно, тревожность может вызвать не только факт не усвоения, но и не следования гендерным стереотипам (Вейнингер, 2012). Кроме того, как мы отметили вначале нашей работы, современный мир предоставляет нам многообразие фундаментальных свойств, в число которых входят и гендерные стереотипы. Тем самым отметим, что фактором, провоцирующим тревожность, может быть так же неуверенность в «правильности» своей гендерной модели феминности или маскулинности. Но мы же говорим о взаимосвязи. Что есть тревожность? Данный феномен не имеет под собой объективную составляющую, т. е. высокий уровень тревожности может быть взаимосвязан с переживаниями относительно своей гендерной принадлежности, неуверенности в своей поло-ролевой модели, недостаточном усвоении и соотнесении себя гендерному стереотипу. Иными словами, чем выше уровень нашей личностной тревожности, тем больше беспокойства вызывает факт усвоения гендерных стереотипов, а также их верной трактовки. Следовательно, высокая тревожность может вызывать у нас неуверенность в своих гендерных представлениях, а, следовательно, низкие показатели соответствия гендерному стереотипу.

Когда мы говорим о взаимосвязи соотнесения себя гендерному стереотипу и самооценки мы имеем слабую, но положительную корреляцию. Самооценка есть продукт оценки нас самих себя, а также интериоризации оценки окружающих нас людей. Усваивая некие гендерные стереотипы в процессе социализации, мы сталкиваемся с оценкой нас как соответствующих/несоответствующих тому или иному гендеру именно со стороны социума (Шевченко, 2004). В частности, наша самооценка продиктована принятием нас как представителей того или иного гендера и, если эта оценка соответствует моему внутреннему состоянию и бытующим в обществе стереотипами, то я получаю конгруэнтную оценку, не сталкиваюсь с противоречиями, что положительно сказывается на различных аспектах интегральной самооценки.

При применении ранговой корреляции Спирмена в изучении взаимосвязи самооценки и тревожности личности была получена слабая обратная корреляция. Данная стратегия объяснить этот феномен состоит в 
следующем: адекватная, высокая и завышенная самооценка свидетельствуют о более низком уровне личностной тревожности личности. Неслучайно выделяется так же высокая и завышенная самооценка, поскольку, согласно описанию видов самооценки В. В. Новикова и Ю. М. Забродина, люди с высокой самооценкой при допущении ошибок предпочитают не думать о них, а люди с завышенной самооценкой склонны винить в своих проблемах других. Иными словами, при не достижении уровня притязаний такие люди не будут испытывать того внутреннего дискомфорта (тревогу в частности), как личности с низкой самооценкой, переживающие по поводу неудач. Подходя к заключению по данному вопросу, обобщим наши представления: чем выше самооценка личности, тем ниже уровень его тревожности, поскольку адекватная и высокая самооценки свидетельствуют об оптимизме, уверенности в своих силах, активности, адекватному отношению к возможным трудностям. Однако мы говорим о взаимосвязи, поэтому высокий уровень тревожности, в свою очередь, будет взаимосвязан с низкой самооценкой, включающую в себя неуверенность, замкнутость, пассивность, переживания по поводу реальных и возможных неудач.

Для выявления различий в сфере самооценки, личностной тревожности и степени соответствия гендерному стереотипу у мужчин и женщин нами был выбран U-критерий Манна-Уитни. Рассмотрим полученные результаты.

Прежде всего, отметим, что осознание, принятие личностью собственных гендерных стереотипов у мужчин и женщин значимых различий не имеют. Данный факт объясняется тем, что социализацию проходят все, вне зависимости от акушерского пола: и мальчикам, и девочкам в детстве представляется набор различных характеристик, гендерных стереотипов в частности, которые необходимо усвоить и тем, и другим для адаптивной жизни в обществе. Кроме того, отсутствие значимых различий в сфере соответствия гендерному стереотипу объясняется так же “моделью артефакта”. А. Фейнгольд анализируя различные вопросники, пришёл к выводу, то мужчины и женщины стараются дать наиболее приемлемые в данном обществе ответы. Данный вывод автор назвал моделью артефакта: свои личностные характеристики представители различных гендеров стараются пропустить через призму общепринятых характеристик и максимально соотнести их друг с другом. Именно поэтому различные тесты лишь подтверждают гендерные стереотипы, а также соответствие им у мужчин и женщин.

На следующем этапе были получены результаты о большей тревожности женщин, что согласуется с многовековым стереотипом. Сложно сказать, чем конкретно обусловлена большая тревожность женщин: ген- 
ной мутацией, которую обнаружили учёные из Йельского университета, особенностями воспитания, усвоенными стереотипами, положением в обществе, заболеваниями или чем-то ещё, но факт остаётся фактом женщины тревожнее мужчин. Суть этих различий сможет выявить только комплексное обследование большой выборки.

В показателях самооценки между мужчинами и женщинами так же не было выявлено значимых различий. Для объяснения данного факта была взята методика Ю. М. Забродина и В. В. Новикова, изучающую интегральную самооценку личности, которая помогла высказать следующие предположения. Согласно традиционным представлениям, для мужчин и женщин значимыми являются различные жизненные сферы (условно можно выделить сферу деятельности и достижений для мужчин, сферу межличностных отношений и личностных качеств для женщин). Анализируя данные, необходимо отметить, что женщины более высокие значения отдавали своей привлекательности, общительности, искренности и доброте, мужчины - смелости, принципиальности, уму, здоровью, честности.

Заключительным этапом исследования было изучение содержательной структуры гендерных стереотипов мужчин и женщин с помощью представленного инструмента. Характеристики, которые испытуемым необходимо было отнести к категориям «мужчин» или «женщин» были взяты из исследования Дж. Уильямса - это межкультурные стереотипы мужчин и женщин, их обобщённые характеристики без учёта половой принадлежности (поскольку в рамках статьи мы не можем поместить весь набор характеристик, необходимо сделать ссылку на пособие Е. П. Ильина «Пол и гендер» (Ильин, 2003, 2010), где представлен полный перечень качеств, отобранных Дж. Уильямсом). Российские стереотипы - те, которые были получены в результате выбора из предложенных 73 полученных межкультурных стереотипов: они предъявлялись нашим испытуемым без указания принадлежности к мужчине или женщине. Испытуемые должны были отметить качества, которые ассоциируются у них только с мужчинами или только с женщинами.

В исследовании были выявлены ядерные, периферийные и черты, включающие в себя две группы качественно поделённых по коэффициенту дискриминативности.

В целом благодаря данному инструменту изучения гендерных стереотипов был сделан общий вывод о том, что образ типичного мужчины и принадлежащих ему характеристик в представлениях мужчин и женщин в российском стереотипе более аморфен, т.к. многие типично мужские черты различны у женщин и мужчин. В то же время, образ типичной женщины претерпевает так же некоторые изменения, которые связаны отрицанием некоторых типичных женских характеристик как ядерных. 
Полученные данные свидетельствуют о том, что в российском обществе стереотип мужчины является более неопределённым, чем женский (первый этап феминизации). Следовательно, мы можем сказать, что стереотип женщины является более стабильным. На втором этапе феминизации возможен расплывчатый образ для женщин, а уже на третьем могут создаваться новые стереотипы.

В представлениях женщин о мужчинах мы получили черты, которые с равной вероятностью принадлежат и мужчинам, и женщинам (фактически 50\% на 50\%). Такую же картину мы получили в представлении мужчин о женщинах.

Если обратиться к выделенному нами андрогинному мужскому и женскому российскому стереотипу, то следует заметить, что российский перечень андрогинных черт в большей мере совпадает с межкультурным мужским стереотипом. Возможно, что в историческом сознании образ мужчины сформировался раньше и сейчас уже больше андрогинен, чем женский, однако при опросе Дж. Ульямсом представителей 25 стран он рассматривался как мужской (всё же отметим, что опрос этот проводился в XX веке, в другую эпоху, что нельзя не учитывать).

Наибольшую сложность в отнесении россиянами (без учёта пола) черт к конкретному полу (т. е. андрогинных) вызывают черты приписываемые мужчине в межкультурном стереотипе. Следовательно, наибольшую проблематику имеет именно мужской образ в российском современном обществе.

В заключении хотелось бы отметить, что проблема гендерных стереотипов является актуальной, и данное исследование может послужить для дальнейших наработок, в том числе, и разработок практических рекомендаций в области изучения поведения и деятельности мужчин и женщин. Немаловажным является выявленный нами феномен феминизации: необходимо проводить работы не только связанные с изучением содержательной структуры гендерных стереотипов, но также и факторами, влияющими на их изменение.

\section{СПИСОК ЛИТЕРАТУРЫ}

Бендас, Т. В. (2009) Гендерная психология : учебное пособие. СПб. : Питер. 430 с.

Берн, Ш. (2008) Гендерная психология. Законы Мужского и женского поведения. СПб.: Прайм-ЕВРОЗНАК. 320с.

Вейнингер, О. (2012) Пол и характер. СПб. : Астрель. 512 с.

Ильин, Е. П. (2003) Дифференциальная психофизиология мужчины и женщины. СПб. : Питер. 544 с.

Ильин, Е. П. (2010) Пол и гендер. СПб. : Питер. 688 с. 
Клёцина, И. С. (2004) Психология гендерных отношений. Теория и практика. СПб. : Алатейя. 403 с.

Козлов, В. В., Шухова Н. А. (2010) Гендерная психология. СПб. : Речь. 270 c.

Ожигова, Л. Н. (2006) Психология гендерной идентичности личности. К.: Кубанский гос. ун-т. 290 с.

Сидоренко, Е. В. (2003) Методы математической обработки в психологии. СПб. : ООО «Речь». 350 с.

Шевченко, Л. А. (2004) Гендерная психология : учебное пособие. Х. : МИТ. 100 с.

Дата поступления: 15.04.2017 2.

Полянский Андрей Иванович - доцент кафедры общей психологии и истории психологии Московского гуманитарного университета. Адрес: 111395, Россия, г. Москва, ул. Юности, д. 5. Тел.: +7 (499) 374-67-20. Эл. адрес: aipol-69@mail.ru

Сухарева Елена Алексеевна - бакалавр кафедры общей психологии и истории психологии Московского гуманитарного университета. Адрес: 111395, Россия, г. Москва, ул. Юности, д. 5. Тел.: +7 (499) 374-67-20. Эл. адрес: elena.sv.93@gmail.com. Научный руководитель - доцент кафедры общей психологии и истории психологии А. И. Полянский.

Polyanskiy Andrey Ivanovich, Associate Professor, Department of General Psychology and the History of Psychology, Moscow University for the Humanities. Postal address: 5, Yunosti St., Moscow, Russian Federation, 111395. Tel.:+7 (499) 374-67-20. E-mail: aipol-69@mail.ru

Sukhareva Elena Alekseevna, Undergraduate Student, Department of General Psychology and the History of Psychology, Moscow University for the Humanities. Postal address: 5, Yunosti St., Moscow, Russian Federation, 111395. Tel.:+7 (499) 374-67-20. E-mail: Aipol-69@mail.ru. Scientific Adviser - A. I. Polyanskiy, Associate Professor, Department of General Psychology and the History of Psychology.

\section{Для циттрования:}

Полянский А. И., Сухарева Е. А. Взаимосвязь показателя «соответствие гендерному стереотипу» с личностной тревожностью и самооценкой [Электронный ресурс] // Научные труды Московского гуманитарного университета. 2017, № 3. URL: http:// journals.mosgu.ru/trudy/article/view/499 (дата обращения: дд.мм.гг.). DOI: 10.17805/ trudy.2017.3.5 